\title{
INFLUENCE OF THE INK AND SUBSTRATE PROPERTIES ON THE INK TRANSFER IN LITHOGRAPHY
}

\author{
Tomislav Cigula (D), Tamara Tomašegović (D), Tomislav Hudika (D), Davor Donevski \\ University of Zagreb, Faculty of Graphic Arts, Zagreb, Croatia
}

\begin{abstract}
There are many parameters influencing transfer of the printing ink onto the printing substrates. Beside printing press characteristic one of most influential parameters is interface interactions in the offset blanket-printing ink-printing substrate system.

The aim of this paper is to determine printing ink and substrate properties as an influential parameter to the printing ink transfer, i.e. properties of the imprint. To achieve this goal, this research will be conducted in three steps. First, characterization of the printing substrates (coated and uncoated samples) and printing ink will be performed. The printing substrates will be characterized by determining smoothness of paper according to Bekk and surface free energy, while to printing ink's tack will be determined to detect property of the printing ink influencing the ink transfer. In the second stage a multipurpose printability testing machine will be used to produce laboratory prints. Finally, the prints will be characterized by conducting optical measurements (spectrophotometric and densitometric measurements) and determination of physical properties of the ink film (mass of the dried ink film).

The results of the research have proven that characteristics of the printing substrate and tack of the printing ink influence transfer of the printing ink onto the printing substrate, i. e. print quality.
\end{abstract}

Key words: lithography, printing ink, printing substrate, ink film

\section{INTRODUCTION}

Although other printing techniques are increasing their market share, offset is still the leader in the market share of the printing industry (Smith, 2017). The offset printing is a complex process where difference between printing and non-printing areas on the printing plate is achieved by their opposite physical-chemical properties (Kipphan, 2001) (Wilson, 2005). To disable adhesion of the printing ink on the non-printing areas, they must be covered by the water based solution - fountain solution. Furthermore, the ink transfer from the printing plate to the printing substrate is performed by the blanket cylinder (Figure 1).

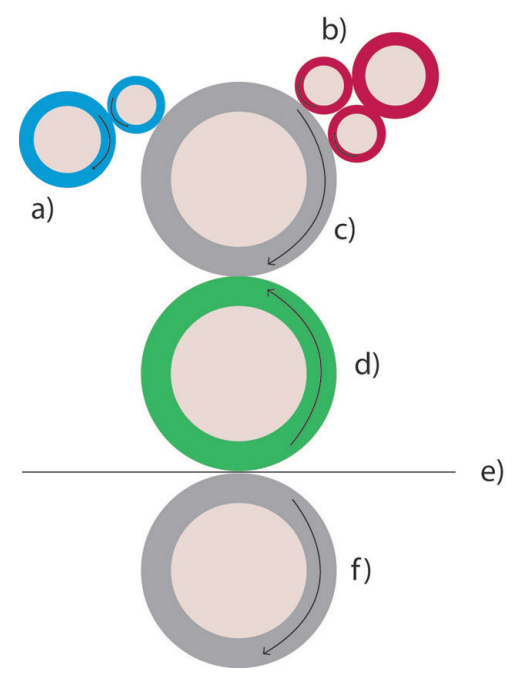

Figure 1: Basic offset printing unit: a) wetting unit, b) inking unit, c) plate cylinder, d) blanket cylinder, e) substrate and f) impression cylinder

The quality of the printing is influenced by many parameters including digital files, materials used in the process (printing substrate, printing ink, fountain solution, printing plate) and the process parameters of 
printing press (e.g. printing speed. pressure, register, etc.) (Gallus, 2016). The scheme of the printing process parameters can be seen in Figure 2.

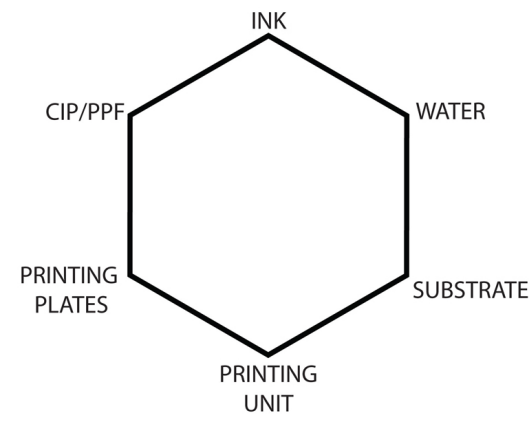

Figure 2: Offset printing process parameters

In order to achieve high printing quality, determination of the influence of each process parameters has to be performed and evaluated. In this paper investigation of the printing substrate and printing ink interaction has been performed.

\section{MATERIALS AND METHODS}

To achieve the aim of the research - determine printing ink and substrate properties as an influential parameter to the printing ink transfer, the research had three stages:

1. determination of the printing substrate and printing ink properties

2. making the imprints in laboratory surroundings

3. determination of the imprint characteristics

The printing substrates used in this research were two types of the fine art paper (gloss and matte coated) in the grammage of $300 \mathrm{gm}^{-2}$ and coated box board in the grammage of $305 \mathrm{gm}^{-2}$. On the other hand, printing inks were standard process offset inks (cyan, magenta, yellow and black).

Determination of the paper smoothness according to Bekk was performed using the ModularLine Smoothness Tester (Frank-Pti, n.d.).

To calculate the surface free energy of the printing substrates, contact angles of three reference liquids (water, glycerol, diiodomethane) were measured on each substrate by the use of Dataphysics OCA 30 goniometer. Sessile drop method was used to determine contact angle value. Measurements were conducted at room temperature. Drop of liquids was set to $1 \mu \mathrm{l}$, and the contact angle was measured 4 seconds after the first contact between solid and liquid. After that, surface free energy (SFE) and its polar $\left(\right.$ SFE $\left.^{p}\right)$ and dispersive (SFE ${ }^{d}$ ) components were calculated in the Dataphysics' SCA 20 software by applying OWRK method (Owens et al, 1969).

The determination of the printing ink tack was performed using a IGT TackOscope III unit (IGT, n.d.). The measurements were conducted according to the ISO 12634:2017. This procedure included three steps $t$ fixed temperature of $30^{\circ} \mathrm{C}$. First $0.4 \mathrm{~cm}^{3}$ of ink was applied onto the distribution roller and the test was started by 30 s of distribution time at the speed of $50 \mathrm{~m} / \mathrm{min}$. In second stage measurements of the tack was conducted at speed of $100 \mathrm{~m} / \mathrm{min}$ for 60 seconds. In the third step tack was measured at the speed of $50 \mathrm{~m} / \mathrm{min}$ for 90 seconds.

The sample imprints were produced in the laboratory by the use of the Pruefbau MZ II Multipurpose Printability Testing System (Pruefbau, n.d.). This laboratory unit enables printing in precisely defined conditions regarding amount of fountain solution and printing ink, printing speed and printing pressure. For the purpose of this experiment, the printing speed was $1 \mathrm{~m} / \mathrm{s}^{-1}$, printing pressure was $150 \mathrm{Ncm}^{-2}$, distribution time for the ink was set at $30 \mathrm{~s}$, ink amount put into the inking unit was $0.2 \mathrm{~cm}^{3}$ and the application of the ink on the rubber form cylinder was set at 30 cycles.

Imprints were evaluated by weighing the dry ink film and the measuring colorimetric and densitometric values. The colorimetric and densitometric values were obtained using X-Rite eXact spectrophotometer (X-Rite, n.d.). Dry ink film was determined as difference between mass of the imprint and the mass of the printing substrate. Weighing was performed using Mettler Toledo XS205DU balance (Mettler Toledo, n.d.). 


\section{RESULTS AND DISCUSSION}

In table 1 one can see characteristics of the printing substrates (fine art paper gloss designates as GLOSS, fine art paper matte designated as MATTE and coated box board designated as BOARD).

Table 1: Determined characteristics of printing substrates

\begin{tabular}{|c|c|c|c|}
\cline { 2 - 4 } \multicolumn{1}{c|}{} & GLOSS & MATTE & BOARD \\
\hline $\begin{array}{c}\text { Smoothness of paper } \\
\text { Bekk method [s] }\end{array}$ & $535.98 \pm 20.03$ & $114.54 \pm 3.2$ & $102.26 \pm 5.32$ \\
\hline $\begin{array}{c}\text { Surface free energy } \\
(\mathrm{SFE})[\mathrm{mN} / \mathrm{m}]\end{array}$ & 42.15 & 35.71 & 39.51 \\
\hline $\begin{array}{c}\text { polar part of SFE (SFEp) } \\
{[\mathrm{mN} / \mathrm{m}]}\end{array}$ & 7.60 & 7.02 & 4.01 \\
\hline $\begin{array}{c}\text { dispersive part of SFE } \\
\left(\mathrm{SFE}^{\mathrm{d}}\right)[\mathrm{mN} / \mathrm{m}]\end{array}$ & 34.55 & 28.69 & 35.5 \\
\hline
\end{tabular}

As one can see in table 1, GLOSS paper has by far the highest smoothness, and highest surface free energy and water absorption. On the other hand, BOARD has much lower polar part of the surface free energy in comparison to the GLOSS and MATTE.

Tack of printing ink is showed in table 2. Tack values presented in table 2 are the values at the end of the certain stage (measuring at the speed of 100 and speed of 50 ) as described in previous section.

Table 2: Ink tack value

\begin{tabular}{|c|c|c|c|c|}
\cline { 2 - 5 } \multicolumn{1}{c|}{} & Cyan & Magenta & Yellow & Black \\
\hline Tack at 100 & $164.56 \pm 5.22$ & $170.69 \pm 1.36$ & $223.35 \pm 1.81$ & $162.98 \pm 2.27$ \\
\hline Tack at 50 & $145.72 \pm 2.72$ & $154.12 \pm 0.68$ & $192.71 \pm 0.68$ & $144.59 \pm 0.23$ \\
\hline
\end{tabular}

The tack values are higher at higher speed. The highest tack value has yellow ink while black ink has lowest tack. it can also be seen that differences between tack black, cyan and magenta is small, and yellow's tack is ca. one third higher than the tack of other inks.

Printing substrates was performed in laboratory using Printability Testing System with equal printing conditions (printing speed, printing pressure, amount of the printing ink) for all substrates and printing inks. In Figure 3 and 4 one can see the results of the imprint evaluation.

It is clearly visible that highest density is achieved when printing black printing ink on all substrates and lowest density values are measured on the substrates when printing yellow printing ink. Furthermore, higher values are achieved on fine arts paper in comparison to the coated board.

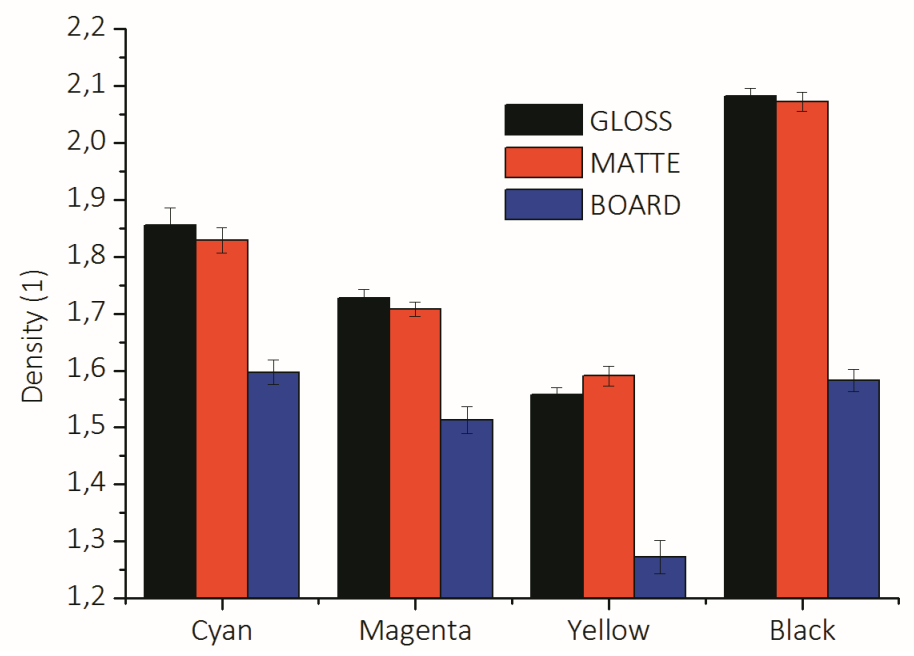

Figure 3: Density of process colours 
The presented results of imprints density are opposite to the ink tack values. The ink tack values are given as a computation of a measured force when ink film is splitting between two rollers. Higher the ink splitting, higher the tack value, meaning that lower thickness of the ink film will be split and transferred onto the printing substrate as can also be seen in Figure 4.

On the other hand, it could be seen that higher smoothness and/or surface free energy (SFE) of the printing substrate leads to the higher density of the printed inks on it. Smoothness of the substrate means that the ink film formed on the substrate surface would be homogenous without higher amount of ink staying in the micro valleys on the substrate surface.

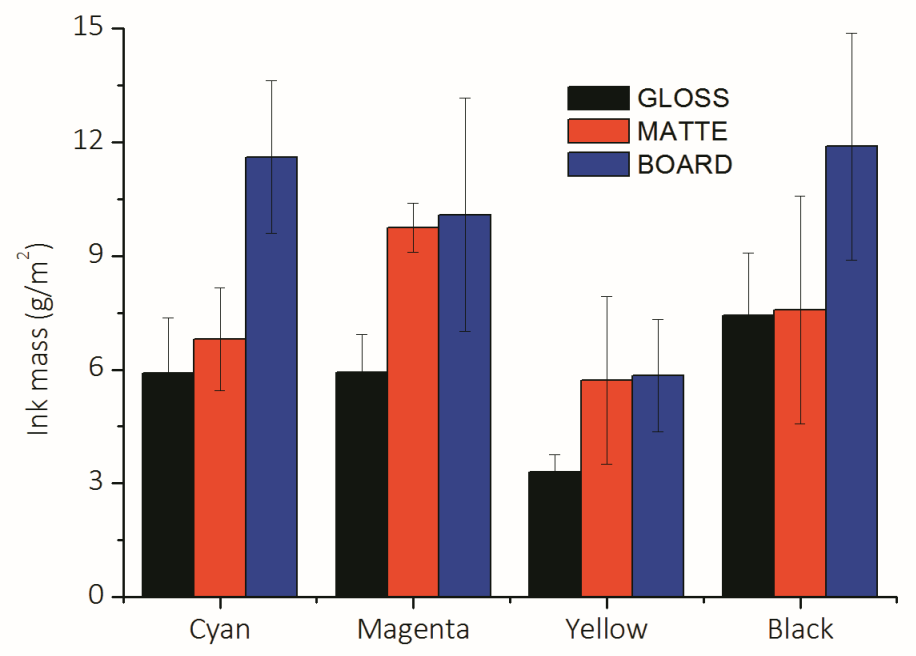

Figure 4: Mass of the dried ink layer

Opposite to the density values, the transferred ink film mass is highest on the BOARD printing substrate and lowest on the GLOSS substrate. Moreover, difference between ink film mass on the fine arts paper is small for cyan and black but high for magenta and yellow, where ink film mass on the MATTE is similar to the mass on the BOARD.

The results presented in Figure 3 and 4 show that ink on the BOARD substrate is better absorbed into the substrate causing higher reflection of light from the surface, i. e. lower density value. This is probably consequence of bulkier structure of the BOARD substrate. Nevertheless, the method used for the dried ink film mass computation is showing higher deviations, so it should be improved in the future evaluations. Calculation of the colour difference was made using $\Delta \mathrm{E}_{\mathrm{ab}}$ formula as defined in the ISO 12647-2: 2013. The results of the colour difference calculation are presented in Figure 5. The signs in the graph designate printing substrate combinations which were used in calculation.

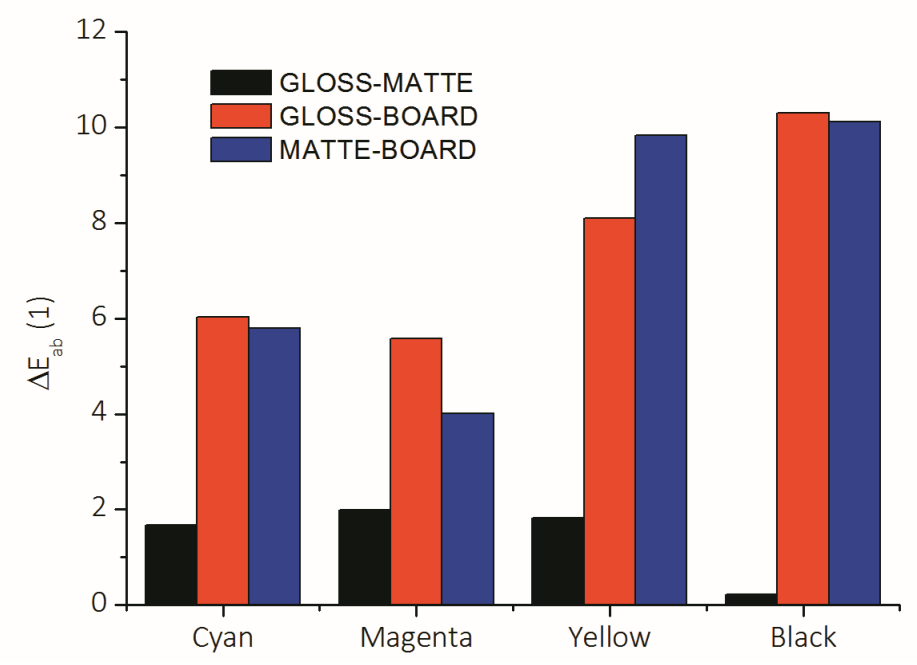

Figure 5: $\Delta E$ value between colours printed on investigated printing substrates 
The highest difference between fine arts papers and paper board is present when printing black ink. Black ink is achromatic and higher density (Figure 3) leads to the lower $L$ value, i.e. high colour difference. Similar behaviour is present in the reproduction of yellow ink. Higher ink film density on the substrate surface increases the chroma of the ink. The colour differences between fine art papers and paper board are not acceptable, except for MATTE-BOARD difference in magenta.

\section{CONCLUSIONS}

The hypothesis of this research was that printing substrate's and printing ink's properties influence the ink transfer during printing process. For the purpose of this research some material properties, including printing substrate's surface free energy and smoothness and printing ink's tack value, were determined. To evaluate printing ink transfer, density, dry ink film mass and colour difference were measured.

The results of the investigation showed that chosen printing substrates have similar surface free energy value but different smoothness. On the other hand, yellow ink had much higher tack than other process inks. The obtained density values were much higher on the fine art papers, but the mass of the dried ink film was higher on the paper board. The colour differences were negligible between fine art papers, but unacceptable between fine arts papers and the paper board.

From the results of this research one can conclude that investigated printing substrates and printing ink properties influence ink transfer in the printing process. The process should be adjusted according to the materials properties. Furthermore, one should take into account the printing ink usage when determining printing process costs as it can be seen that density of the colour is not linear dependant to the ink mass on the imprint.

In addition, in the future research it is planned include determination of more printing substrate properties to better determine more precise links between imprint and printing substrate properties.

\section{ACKNOWLEDGMENTS}

This research is a part of the project UIP-2017-05-4081, Development of the model for production efficiency increase and functionality of packaging, supported by Croatian Science Foundation.

\section{REFERENCES}

[1] Frank-Pti, ModularLine Smoothness Tester, Frank-Pti, URL: https://www.frankpti.com/index.php?controller=dataset\&function=show_detail\&id=96 (last request: 2018-08-28).

[2] Gallus, Series of articles on factors influencing quality in offset printing (part 4), Gallus, 2016, URL: https://www.gallus-group.com/en/gallus/whitepaper/2016/03/04/series-of-articles-on-factorsinfluencing-quality-in-offset-printing (last request: 2018-09-22).

[3] IGT, TackOscope III, IGT Testing Systems Pte Ltd, URL: http://www.igt.com.sg/products/details/tackoscope-iii (last request: 2018-09-14).

[4] International Organization for Standardization (ISO), ISO 12634:2017 Graphic technology -Determination of tack of paste inks and vehicles by a rotary tackmeter, International Organization for Standardization, 2017.

[5] International Organization for Standardization (ISO), ISO 12647-2:2013 Graphic technology -Process control for the production of half-tone colour separations, proof and production prints -Part 2: Offset lithographic processes, International Organization for Standardization, 2013.

[6] Kipphan, H.: "Handbook of Print Media", (Springer, Berlin, 2001).

[7] Mettler Toledo, Balance XS205DU, Mettler Toledo, URL: https://www.mt.com/hr/hr/home/products/Laboratory_Weighing_Solutions/Analytical/Excellence/ XS_Analytical_Balance/XS205DU.html (last request: 2018-09-25).

[8] Owens, D. K., Wendt, R. C.: "Estimation of the surface free energy of polymers", Journal of Applied Polymer Science 13(8), 1741-1747, 1969. doi: 10.1002/app.1969.070130815.

[9] Pruefbau, prüfbau Multipurpose Printability Testing Instrument MZ II and MZ E, Pruefbau, URL: http://pruefbau.com/en/offsetdruck/ (last request: 2018-09-21). 
[10] Smith, S.: "Digital printing to continue to take market share from offset presses", Smithers Pira, 2017, URL: https://www.smitherspira.com/news/2017/april/digital-print-takes-market-share-fromoffset (last request: 2018-10-02).

[11] Wilson D. G.: "Lithography primer", 3rd ed, (PIA/GATFPress, Pittsburg, USA, 2005).

[12] X-Rite, eXact Spetrophotometer, X-Rite, URL: https://www.xrite.com/categories/portablespectrophotometers/exact (last request: 2018-09-24).

(c) $\underset{\text { ax }}{0}$

(C) 2018 Authors. Published by the University of Novi Sad, Faculty of Technical Sciences, Department of Graphic Engineering and Design. This article is an open access article distributed under the terms and conditions of the Creative Commons Attribution license 3.0 Serbia (http://creativecommons.org/licenses/by/3.0/rs/). 